\title{
МАТЕМАТИЧНА МОДЕЛЬ СИСТЕМИ ОРІЕНТАЦЇ̈ РОТОРА ВІТРОУСТАНОВКИ ЗА РАХУНОК ВЛАСНОЇ ПАРУСНОСТІ РОТОРА
}

\author{
В.М. Головко, проф., докт. техн. наук, В.П. Коханєвич, канд. техн. наук, М.О. Шихайлов наук. співроб. \\ Інститут відновлюваної енергетики НАН України, \\ 02094, вул. Гната Хоткевича, 20А, м. Київ, Україна.
}

\begin{abstract}
Незважаючи на значний досвід в проектуванні вітроустановок малої потужності в прочесі їх експлуатації виникають руйнування окремих елементів установки, які можуть призвести до руйнування установки в иіілому. Одним з важливих чинників, що призводить до руйнування елементів, зокрема лопатей, є гіроскопічні навантаження, щчо виникають в них при орієнтації ротора за напрямком повітряного потоку. При цььму необхідно зауважити, що перед конструкторами стоїть певна дилема. 3 однієї сторони збільшення кутової швидкості призводить до зменшення енергетичних втрат при орієнтації ротора, а з іншої-до збільшення гіроскопічних навантажень в лопаті.

На сьогоднішній день в ряді робіт запропоновані математичні моделі систем орієнтації ротора за напрямком повітряного потоку за рахунок флюгерної площини хвоста. При иьому використовуються різноманітні конструктивні схеми даноі системи орієнтачії ротора, такі як підпружинений хвіст, хвіст на косому шарнірі та інші. Система орієнтації ротора за рахунок власної парусності ротора практично недосліджена $і$ потребує теоретичних розробок та подальшої їх експериментальної перевірки.

В даній роботі пропонується розробити математичну модель системи орієнтації ротора вітроустановки за рахунок власної парусності ротора із врахуванням ряду параметрів та характеристик даної системи орієнтації. Запропонована математична модель орієнтаиї ротора дозволило отримати рівняння для розрахунку кутових швидкостей орієнтації ротора в залежності від швидкостей вітру, кута відхилення ротора від напрямку повітряного потоку та ряду конструктивних параметрів системи орієнтації ротора. Отримані кутові швидкості орієнтації ротора дозволяють визначити енергетичні втрати та гіроскопічні навантаження на елементи конструкції вітроустановки в процесі орієнтачії ротора. Дані рівняння також дозволяють визначити параметри, якими можна впливати на величину кутовоі швидкості орієнтаиії ротора, такі як відстань від вісі обертання гондоли до площини ротора та коефіиієнт демпфування відповідних пристроїв, щчо дозволяє вибрати раціональну величину кутової швидкості орієнтації ротора з урахуванням можливих втрат виробітку вітроустановкою та величин гіроскопічних навантажень в лопатях $і$ елементах гондоли. Бібл. 9, рис. 1.
\end{abstract}

Ключові слова: вітроенергетика, вітроустановка, орієнтація ротора за рахунок власної парусності.

\section{MATHEMATICAL MODEL OF THE SYSTEM OF ORIENTATION OF THE ROTOR OF A WIND INSTALLATION AT THE ACCOUNT OF OWN ROTOR OWN SAWING}

\author{
V. Golovko, professor, doctor of technical science, V. Kokhanevich, candidate of technical science, M. Shikhailov, researcher
}

Institute of Renewable Energy of the National Academy of Sciences of Ukraine,

02094, 20A Hnata Khotkevycha St., Kyiv, Ukraine.

Despite considerable experience in the design of low-power wind turbines during their operation, destruction of individual elements of the installation occurs, which can lead to the destruction of the installation as a whole. One of the important factors that leads to the destruction of elements, in particular the blades, is the gyroscopic loads that occur in the blades when the rotor is oriented in the direction of air flow. It should be noted that the designers face a certain dilemma. On the one hand, an increase in angular velocity leads to a decrease in energy losses during the orientation of the rotor, and on the other hand, to an increase in gyroscopic loads in the blades.

To date, a number of works have proposed mathematical models of rotor orientation systems in the direction of air flow due to the tail vane plane. In this case, various structural schemes of this rotor orientation system are used, such as a spring-loaded tail, a tail on an oblique hinge, and others. The rotor orientation system due to its own rotor windage is practically unexplored and requires theoretical developments and their subsequent experimental verification.

In this paper, it is proposed to develop a mathematical model of the orientation system of the rotor of a wind turbine due to its own windage of the rotor, taking into account a number of parameters and characteristics of this orientation system. The proposed mathematical model of rotor orientation made it possible to obtain equations for calculating the rotor orientation angular velocities depending on wind speeds, the angle of the rotor deviation from the air flow direction, and a number of design parameters of the rotor orientation system. The obtained angular velocity of the orientation of the rotor allows you to determine the energy loss and gyroscopic loads on the structural elements of the wind turbine during the orientation of the rotor. These equations also allow you to determine the parameters that can affect the value of the angular velocity of the orientation of the rotor, such as the distance from the axis of rotation of the nacelle to the plane of the rotor and the damping coefficient of the corresponding devices, allows you to choose a rational value of the angular velocity of orientation of the rotor, taking into account possible losses generated by the wind turbine and gyroscopic values loads in the blades and elements of the gondola. Ref. 9, fig. 1 .

Keywords: wind power, wind turbine, rotor orientation due to its own windage. 


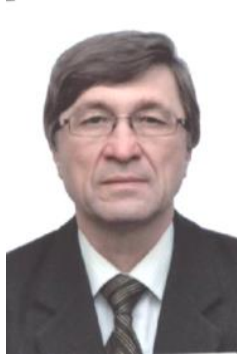

В.М. Головко V. Holovko

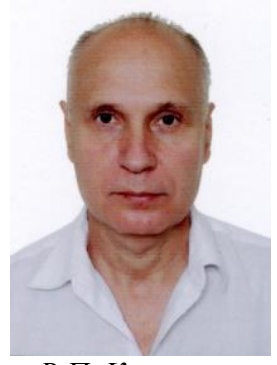

В.П. Коханєвич V. Kokhanievych

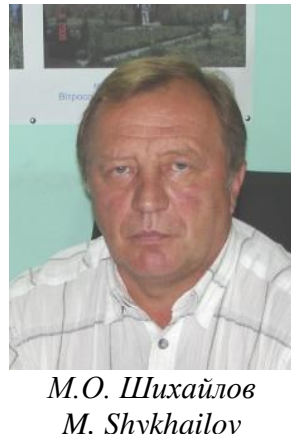

Відомості про автора: науковий співробітник Інституту відновлюваної енергетики НАН України.

Освіта: закінчив 1979 р. Київський політехнічний інститут за спеціальністю «Гідропневмоавтоматика та гидропривод». Наукова сфера: вітроенергетика, вітроустановки малої потужності, системи управління.

Публікації: 207.

ORCID: 0000-0003-1845-9904

Контакти: тел./факс: +38-044-206-28-09 e-mail: renewable@ukr.net
Author information: chief researcher at Institute for Renewable Energy, National Academy of Sciences of Ukraine.

Education: graduated from the Ukrainian Agricultural Academy in 1977 with the degree of «Electrification of Agriculture».

Reasearch area: renewable sources of energy, wind power systems, small capacity wind units, autonomous power systems.

Publications: 162

ORCID: 0000-0003-0195-9654

Contacts: tel./fax: +38-044-206-28-09

e-mail: renewable@ukr.net

Author information: senior researcher at Institute for Renewable Energy, National Academy of Sciences of Ukraine.

Education: graduated from the Kyiv Polytechnic Institute in 1979 with the specialization «Technology of Machine-Building, Metal Cutting Machines and Tools».

Reasearch area: power systems, converting types of energy, automation and modeling processes. wind power systems, small capacity wind units, control systems and protect.

Publications: 121

ORCID: 0000-0003-0033-1355

Contacts: tel./fax: +38-044-206-28-09

e-mail: renewable@ukr.net

Author information: researcher in at Institute for Renewable Energy, National Academy of Sciences of Ukraine.

Education: graduated from the Kyiv Polytechnic Institute in 1979 with the specialty «Hydropneumatic and Hydraulic Drive».

Reasearch area: wind power systems, small capacity wind units, control systems.

Publications: 207.

ORCID: 0000-0003-1845-9904

Contacts: tel./fax: +38-044-206-28-09

e-mail: renewable@ukr.net

\section{Перелік використаних позначень та скорочень:}

$\rho$ - густина повітря;

$v$-швидкість незбуреного вітрового потоку;

$F$ - площа обмаху ротора;

$V$ - швидкість повітряного потоку;

$R$ - радіус ротора

$\gamma$ - кут повороту ротора;

$\gamma_{0}$ - кут набігання повітряного потоку на ротор при зміні напрямку вітру;

$B$ - сила лобового тиску на ротор;

$C_{T}$ - коефіцієнт лобового тиску;

Вступ. Незважаючи на значний досвід в проектуванні вітроустановок малої потужності [1] в процесі їх експлуатації виникають руйнування окремих елементів установки, які можуть призвести до руйнування установки в цілому. Одним 3 важливих чинників, що
$k_{T}$ - коефіцієнт тангенціальної сили;

$\rho$ - питома густина повітря;

$\omega_{P}-$ кутова швидкість обертання ротора;

$\omega$ - кутова швидкість орієнтації ротора за напрямком повітряного потоку;

$J_{P}$ - момент інерції ротора;

$J_{\Gamma}$ - момент інерції гондоли відносно вісі її повороту;

$k_{Д_{\Pi}}-$ коефіцієнт демпфування пристрою.

призводить до руйнування елементів, зокрема лопатей, $\epsilon$ гіроскопічні навантаження, що виникають в лопатях при орієнтації ротора за напрямком повітряного потоку [2]. При цьому необхідно зауважити, що перед конструкторами стоїть певна дилема. 3 однієї сторони збільшення 
кутової швидкості призводить до зменшення енергетичних втрат при орієнтації ротора [3], а 3 іншої - до збільшення гіроскопічних навантажень в лопаті.

Постановка завдання. На сьогодні в ряді робіт [4 - 9] запропоновані математичні моделі систем орієнтації ротора за напрямком повітряного потоку за рахунок флюгерної площини хвоста. При цьому використовуються різноманітні конструктивні схеми даної системи орієнтації ротора, такі як підпружинений хвіст, хвіст на косому шарнірі та інші. Система орієнтації ротора за рахунок власної парусності ротора практично не досліджена i потребує теоретичних розробок та подальшої їх експериментальної перевірки.

В даній роботі пропонується розробити математичну модель системи орієнтації ротора вітроустановки за рахунок власної парусності ротора 3 рахуванням ряду параметрів та характеристик системи орієнтації.

Результати досліджень. Розвертання ротора за напрямком повітряного потоку при його зміні в загальному випадку описується наступним диференційним рівнянням:

$$
J_{\Gamma} \cdot \frac{d^{2} \gamma}{d t^{2}}=\sum M_{Z},
$$

де $J_{\Gamma}$ - момент інерції гондоли відносно вісі іï повороту (осі $Z) ; \gamma$ - кут повороту ротора; $\sum M_{Z}$ - алгебраїчна сума моментів, що діють на ротор та елементи гондоли в процесі орієнтації ротора за напрямком повітряного потоку, відносно вісі іiі повороту.

Розглянемо схему сил, що діють на ротор та елементи гондоли в процесі орієнтації ротора за напрямком повітряного потоку (рис. 1), та проаналізуємо сили, що входять у вираз 1.

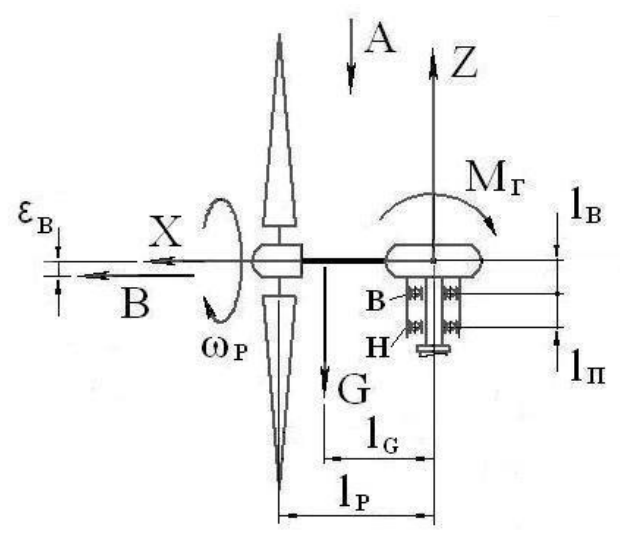

Вид А

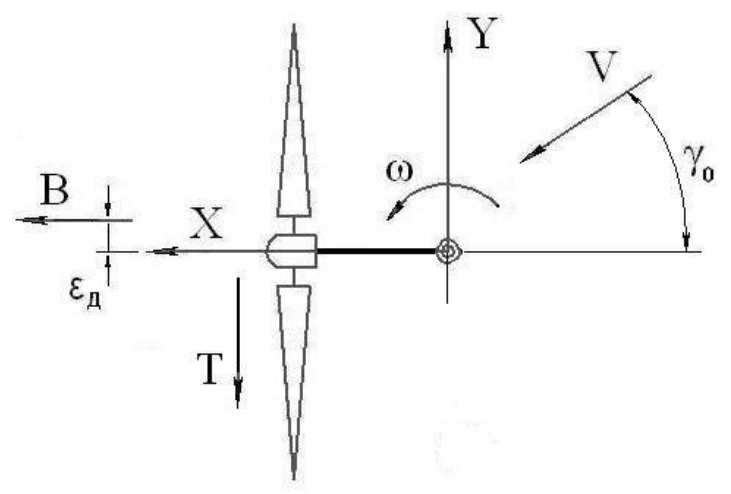

Рис. 1. Схема сил, що діють на ротор та елементи гондоли в процесі оріснтації ротора в напрямку повітряного потоку.

Fig. 1. Scheme of forces acting on the rotor and gondola elements in the process of orientation of the rotor in the direction of air flow. 


$$
\sum M_{Z}=M_{P}-M_{T p}-M_{\text {Д }},
$$

де $M_{P}-$ поворотний момент від аеродинамічних сил, що діють на ротор; $M_{T p}-$ момент від сил тертя в опорно-поворотному пристрою; $M_{\text {д }}-$ момент демпфування.

Розглянемо вищенаведені моменти та сили. Поворотний момент від аеродинамічних сил, що діють на ротор, буде складати:

$$
M_{P}=M_{B}+M_{T},
$$

де $M_{B}$ - поворотний момент від сили лобового тиску; $M_{T}$ - тангенціальна складова від сили лобового тиску.

Поворотний момент від сили лобового тиску спричиняється зміщенням центру лобового тиску відносно центру ротора при набіганні повітряного потоку під кутом $\gamma$ до площини ротора. Дане питання було розглянуто в $[5,9]$ та отримано вираз $M_{B}$ :

$$
M_{B}=\frac{\pi}{4} \rho \cdot k \cdot C_{T} \cdot V^{2} \cdot R^{3} \cdot\left(\gamma_{0}-\gamma\right) \cdot \cos ^{3}\left(\gamma_{0}-\gamma\right),
$$

де $\gamma_{0}-$ кут набігання повітряного потоку на ротор при зміні напрямку вітру (або кут відхилення ротора від напряму повітряного потоку при зміні напрямку вітру); $\rho$ - питома густина повітря; $C_{T}$ - коефіцієнт лобового тиску (у відповідності з теорією Бетца складає $C_{T}=\frac{8}{9}$ ); $k \cong 0,0015$, якщо кут $\gamma$ задається в градусах; $V$ швидкість повітряного потоку; $R$ - радіус ротора.

3 урахуванням значень $\rho, k, C_{T}$ (для $\gamma \mathrm{y}$ радіанах) вираз для поворотного моменту від сили лобового тиску набуде вигляду:

$$
M_{B}=0,075 \cdot V^{2} \cdot R^{3} \cdot\left(\gamma_{0}-\gamma\right) \cdot \cos ^{3}\left(\gamma_{0}-\gamma\right) .
$$

На відміну від систем орієнтації флюгерною площиною тангенціальна складова в системах орієнтації за рахунок парусності ротора і момент від неї буде складати:

$$
M_{T}=k_{T} \cdot \pi \cdot \rho \cdot R^{2} \cdot \frac{V^{2}}{2} \cdot l_{P},
$$

де $k_{T}$ - коефіцієнт тангенціальної сили; $l_{P}$ відстань від вісі обертання головки до площини ротора.

Для $k_{T}$ використаємо вираз із [4], а саме:

$$
k_{T}=0,06 \cdot \sin 0,45 \gamma \text {. }
$$

Тоді поворотний момент від тангенціальної сили можна записати як:

$$
\begin{aligned}
M_{T} & =0,06 \cdot \sin 0,45\left(\gamma_{0}-\gamma\right) \cdot \pi \cdot \rho \cdot R^{2} \cdot \frac{V^{2}}{2} \cdot l_{P}= \\
& =0,12 \cdot \sin 0,45\left(\gamma_{0}-\gamma\right) \cdot R^{2} \cdot V^{2} \cdot l_{P} .
\end{aligned}
$$

3 урахуванням виразів для 5 та 6 запишемо вираз для поворотного моменту від аеродинамічних сил, що діють на ротор:

$$
\begin{aligned}
& M_{P}=0,075 \cdot V^{2} \cdot R^{3} \cdot\left(\gamma_{0}-\gamma\right) \cdot \cos ^{3}\left(\gamma_{0}-\gamma\right)+ \\
& \quad+0,12 \cdot \sin 0,45\left(\gamma_{0}-\gamma\right) \cdot R^{2} \cdot V^{2} \cdot l_{P} .
\end{aligned}
$$

До моменту від сил тертя в опорноповоротному пристрою даної схеми орієнтації входять наступні складові моменти:

$$
M_{T p}=\left(M_{T p}\right)_{B}+\left(M_{T p}\right)_{M_{\Gamma}}+\left(M_{T p}\right)_{G},
$$

де $\left(M_{T p}\right)_{B}-$ момент тертя від сили лобового тиску на ротор; $\left(M_{T_{p}}\right)_{M_{\Gamma}}$ - момент тертя від дії гіроскопічного моменту; $\left(M_{T p}\right)_{G}-$ момент тертя від маси гондоли.

При розрахунку моменту тертя від сили лобового тиску на ротор потрібно враховувати зміщення центру тиску в вертикальній площині в напрямку обертання ротора на величину $\varepsilon_{B}$. Так як величина даного зміщення незначна, то нею можна знехтувати. Тоді вираз для $\left(M_{T p}\right)_{B}$ набуде наступного вигляду:

$$
\left(M_{T p}\right)_{B}=B \cdot\left(f_{B} \cdot r_{B} \frac{l_{B}+l_{\Pi}}{l_{\Pi}}+f_{H} \cdot r_{H} \frac{l_{B}}{l_{\Pi}}\right),
$$

де $\quad B=\frac{\pi}{2} \rho \cdot C_{T} \cdot V^{2} \cdot R^{2} \cdot \cos ^{2}\left(\gamma_{0}-\gamma\right) \quad$ - сила лобового тиску на ротор; $f_{B}$ та $f_{H}$ - коефіцієнти тертя в верхньому та нижньому підшипниках; $r_{B}$ та $r_{H}$ - середні значення радіусів верхнього та нижнього підшипників; $l_{\Pi}-$ відстань між підшипниками; $l_{B}-$ відстань від верхнього підшипника до вісі обертання ротора.

Зазвичай верхній та нижній підшипник,що встановлюються в опорно-поворотному пристрої, одного типорозміру, тобто можна записати, що $f_{B}=f_{H}=f$ та $r_{B}=r_{H}=r .3$ урахуванням даного припущення вираз для $\left(M_{T p}\right)_{B}$ можна записати як: 


$$
\begin{aligned}
& \left(M_{T p}\right)_{B}=\frac{\pi}{2} \rho \cdot C_{T} \cdot V^{2} \cdot R^{2} \times \\
& \times \cos ^{2}\left(\gamma_{0}-\gamma\right) \cdot f \cdot r\left(\frac{2 l_{B}+l_{\Pi}}{l_{\Pi}}\right) .
\end{aligned}
$$

Відповідно, з урахуванням значень $\rho, C_{T}$, момент тертя від сили лобового тиску на ротор складе:

$$
\begin{gathered}
\left(M_{T p}\right)_{B}=1,74 \cdot V^{2} \cdot R^{2} \times \\
\times \cos ^{2}\left(\gamma_{0}-\gamma\right) \cdot f \cdot r\left(\frac{2 l_{B}+l_{\Pi}}{l_{\Pi}}\right) .
\end{gathered}
$$

Момент $\left(M_{T p}\right)_{G}$ буде складати:

$$
\begin{gathered}
\left(M_{T p}\right)_{G}=G \cdot f \cdot r+\frac{G \cdot l_{G}}{l_{\Pi}} \cdot f \cdot r= \\
=G \cdot f \cdot r \cdot \frac{l_{\Pi}+l_{G}}{l_{\Pi}},
\end{gathered}
$$

де $l_{G}$ - відстань від вісі обертання головки до центру ваги головки.

Момент тертя від дії гіроскопічного моменту складає:

$$
\left(M_{T p}\right)_{M_{\Gamma}}=\frac{M_{\Gamma}}{l_{\Pi}}\left(f_{B} \cdot r_{B}+f_{H} \cdot r_{H}\right)=\frac{2 M_{\Gamma}}{l_{\Pi}} \cdot f \cdot r .
$$

3 урахуванням виразу для гіроскопічного моменту $M_{\Gamma}=2 J_{P} \cdot \omega_{P} \cdot \omega$ вираз для моменту тертя від його дії набуде вигляду:

$$
\left(M_{T_{p}}\right)_{M_{\Gamma}}=\frac{2 J_{P} \cdot \omega_{P} \cdot \omega}{l_{\Pi}} \cdot f \cdot r,
$$

де $J_{P}$ - момент інерції ротора; $\omega_{P}-$ кутова швидкість обертання ротора; $\omega-$ кутова швидкість обертання гондоли.

Момент демпфування для даної системи орієнтації буде складати:

$$
M_{\text {Д }}=\left(M_{\text {Д }}\right)_{P}+\left(M_{\text {Д }}\right)_{\Pi} .
$$

де $\left(M_{д}\right)_{P}$ - момент демпфування ротора; $\left(M_{д}\right)_{\Pi}-$ момент демпфування додаткових пристроїв.

Момент демпфування ротора знаходиться з виразу [6]

$$
\left(M_{\text {Д }}\right)_{P}=\frac{\pi}{4} \cdot \rho \cdot R^{4} \cdot V_{n} \cdot C_{T} \cdot \omega,
$$

де $V_{n}$ - нормальна складова від швидкості повітряного потоку, що набігає на ротор.

3 урахуванням значень $\rho$ і $C_{T}$ та того, що $V_{n}=V \cdot \cos \gamma$, запишемо вираз для моменту демпфування ротора в наступному вигляді

$$
\left(M_{\text {Д }}\right)_{P}=0,89 \cdot R^{4} \cdot V \cdot \cos \left(\gamma_{0}-\gamma\right) \cdot \omega .
$$

В конструкціях вітроустановок з системами орієнтації за рахунок парусності ротора на відміну від систем орієнтації за допомогою хвоста використовуються пристрої демпфування повороту гондоли різноманітної конструкції. В загальному випадку вираз для моменту демпфування даних пристроїв можна записати як

$$
\left(M_{\text {д }}\right)_{\Pi}=k_{Д_{\Pi}} \cdot \omega
$$

де $k_{Д_{\Pi}}-$ коефіцієнт демпфування пристрою.

3 урахуванням виразів для $\left(M_{\text {д }}\right)_{P}$ та $\left(M_{\text {Д }}\right)_{\Pi}$ вираз для повного моменту демпфування набуде вигляду

$$
M_{\text {Д }}=0,89 \cdot R^{4} \cdot V \cdot \cos \left(\gamma_{0}-\gamma\right) \cdot \omega+k_{Д_{\Pi}} \cdot \omega .
$$

Як зазначалося вище, рівняння 1 описує рух ротора за напрямом повітряного потоку при зміні напряму вітру. Розкриємо праву частину даного диференційного рівняння, підставимо замість моментів $M_{B}, M_{T p}, M_{\text {д }}$ вирази $13,14,16,21$ та отримаємо рівняння 1 в наступному вигляді:

$$
\begin{aligned}
J_{\Gamma} & \cdot \frac{d^{2} \gamma}{d t^{2}}=0,075 \cdot V^{2} \cdot R^{3} \cdot\left(\gamma_{0}-\gamma\right) \cdot \cos ^{3}\left(\gamma_{0}-\gamma\right)+ \\
& +0,12 \cdot \sin 0,45\left(\gamma_{0}-\gamma\right) \cdot R^{2} \cdot V^{2} \cdot l_{P}- \\
- & x 0,89 \cdot R^{4} \cdot V \cdot \cos \left(\gamma_{0}-\gamma\right) \cdot \omega-k_{Д_{\Pi}} \cdot \omega- \\
- & 1,74 \cdot V^{2} \cdot R^{2} \cdot \cos ^{2}\left(\gamma_{0}-\gamma\right) \cdot\left(\frac{2 l_{B}+l_{\Pi}}{l_{\Pi}}\right) \cdot f \cdot r- \\
& -\frac{2 J_{P} \cdot \omega_{P} \cdot \omega}{l_{\Pi}} \cdot f \cdot r-G \cdot f \cdot r \cdot \frac{l_{\Pi}+l_{G}}{l_{\Pi}} .
\end{aligned}
$$

Рівняння $22 \epsilon$ вихідною математичною моделлю, що дозволяє отримати рівняння кутової швидкості гондоли вітроустановки в залежності від швидкості повітряного потоку $V$, що набігає на ротор, кута відхилення ротора від напрямку повітряного потоку та ряду конструктивних параметрів. При цьому необхідно зауважити, що дана математична модель базується на відповідних допущеннях. Частина цих допущень була проаналізована вище. Крім цього необхідно обумовити допущення, що кутова швидкість обертання ротора $\omega_{P}$ в процесі установлення 
ротора в напрямку повітряного потоку залишається незмінною, так як час орієнтації ротора за напрямом повітряного потоку значно менше часу, що обумовлює суттєве зниження обертів ротора.

Для отримання аналітичного виразу для кутової швидкості орієнтації ротора за напрямком повітряного потоку при зміні напрямку вітру використаємо перетворення [6]:

$$
\frac{d^{2} \gamma}{d t^{2}}=\frac{1}{2} \cdot \frac{d \omega^{2}}{d \gamma}
$$

3 урахуванням виразу 10 запишемо диференційне рівняння 9 в наступному вигляді:

$$
\begin{gathered}
\quad \frac{J_{\Gamma}}{2} \cdot \frac{d \omega^{2}}{d \gamma}=C_{B} \cdot\left(\gamma_{0}-\gamma\right) \cdot \cos ^{3}\left(\gamma_{0}-\gamma\right)+ \\
+C_{B_{T}} \cdot \sin 0,45\left(\gamma_{0}-\gamma\right)-C_{Д_{P}} \cdot \cos \left(\gamma_{0}-\gamma\right) \cdot \omega+ \\
+k_{Д_{\Pi}} \cdot \omega-C_{T_{B}} \cdot \cos ^{2}\left(\gamma_{0}-\gamma\right)-C_{T_{\Gamma}} \cdot \omega-C_{T_{G}} .
\end{gathered}
$$

де $\quad C_{B}=0,075 \cdot V^{2} \cdot R^{3} ; \quad C_{B_{T}}=0,12 \cdot R^{2} \cdot V^{2} \cdot l_{P} ;$

$C_{Д_{P}}=0,89 \cdot R^{4} \cdot V$;

$C_{T_{B}}=1,74 \cdot V^{2} \cdot R^{2} \cdot\left(\frac{2 l_{B}+l_{\Pi}}{l_{\Pi}}\right) \cdot f \cdot r$

$C_{T_{\Gamma}}=\frac{2 J_{P} \cdot \omega_{P}}{l_{\Pi}} \cdot f \cdot r$

$C_{T_{G}}=G \cdot f \cdot r \cdot \frac{l_{\Pi}+l_{G}}{l_{\Pi}}$.

Проведемо інтегрування виразу 22 та отримаємо вираз для кутової швидкості гондоли при орієнтації ротора за напрямком повітряного потоку, а саме:

$$
\begin{aligned}
& \frac{1}{2} \cdot J_{\Gamma} \cdot \omega^{2}=C_{B} \cdot D_{B}+C_{B_{T}} \cdot D_{B_{T}}-C_{Д_{P}} \cdot D_{Д_{P}} \cdot \omega- \\
& -k_{Д_{\Pi}} \cdot \omega \cdot \gamma-C_{T_{B}} \cdot D_{T_{B}}-C_{T_{\Gamma}} \cdot \omega \cdot \gamma-C_{T_{G}} \cdot \gamma+C_{0}^{\prime}, \\
& D_{B}=\frac{1}{36} \cos 3\left(\gamma_{0}-\gamma\right)+\frac{3}{4} \cos \left(\gamma_{0}-\gamma\right)-
\end{aligned}
$$

де

$$
-(1+\gamma)\left(\frac{1}{12} \sin 3\left(\gamma_{0}-\gamma\right)+\frac{3}{4} \sin \left(\gamma_{0}-\gamma\right)\right)
$$$$
D_{B_{T}}=2,2 \cos \left(\gamma_{0}-\gamma\right) ; D_{Д_{P}}=-\sin \left(\gamma_{0}-\gamma\right) \text {; }
$$$$
D_{T_{B}}=\frac{1}{2} \gamma-\frac{1}{4} \sin 2\left(\gamma_{0}-\gamma\right) \text {. }
$$

Для визначення вільного члена, як i в випадку орієнтації ротора за допомогою флюгерної площини [5], приймемо варіант, коли початок відліку кута $\gamma$ співпадає 3 віссю $X$ i, відповідно, $\omega=0$ при $\gamma=0$. Тоді вираз для $C_{0}^{\prime}$ набуде вигляду:

$$
C_{0}^{\prime}=C_{T_{B}} \cdot\left(D_{T_{B}}\right)_{0}-C_{B} \cdot\left(D_{B}\right)_{0}-C_{B_{T}} \cdot\left(D_{B_{T}}\right)_{0},
$$

де $\left(D_{T_{B}}\right)_{0}=-\frac{1}{4} \sin 2 \gamma_{0} ;\left(D_{B_{T}}\right)_{0}=2,2 \cos \gamma_{0}$;

$\left(D_{B}\right)_{0}=\frac{1}{36} \cos 3 \gamma_{0}+\frac{3}{4} \cos \gamma_{0}-\left(\frac{1}{12} \sin 3 \gamma_{0}+\frac{3}{4} \sin \gamma_{0}\right)$.

Як i для системи орієнтації флюгерною площиною [9], так і для системи орієнтації за рахунок парусності ротора, отримане рівняння 25 кутової швидкості гондоли $\omega$ дозволяє провести розрахунки втрат при орієнтації ротора за напрямком повітряного потоку за методикою наведеною розрахунку втрат при орієнтації ротора за напрямком повітряного потоку за методикою наведеною в [3] та гіроскопічних навантажень в лопатях i iнших елементах конструкції вітроустановки [4].

При цьому необхідно зауважити, що коефіцієнти $C_{B}, \quad C_{T_{B}}, \quad C_{B_{T}}$ та $C_{Д_{P}}$ розраховуються для кожної конкретної швидкості вітру, а коефіцієнти $D_{B}, D_{T_{B}}, D_{B_{T}}$, $D_{Д_{P}}$ та $\left(D_{B}\right)_{0},\left(D_{T_{B}}\right)_{0},\left(D_{B_{T}}\right)_{0}$, для кожного відхиленні ротора від напрямку повітряного потоку на певний кут $\gamma_{0}$.

Висновки. 1. Запропонована математична модель орієнтації ротора за рахунок власної парусності ротора, що дозволяє провести розрахунок кутових швидкостей орієнтації ротора в залежності від швидкостей вітру, кута відхилення ротора від напрямку повітряного потоку i ряду конструктивних параметрів системи орієнтації ротора.

2. Отримані рівняння для розрахунку швидкостей орієнтації дозволяють визначити енергетичні втрати та гіроскопічні навантаження на елементи конструкції вітроустановки в процесі орієнтації ротора. Дані рівняння також дозволяють визначити параметри, якими можна впливати на величину кутової швидкості обертання гондоли, такі як відстань від вісі обертання гондоли до площини ротора та коефіцієнт демпфування відповідних пристроїв, що дозволяє забезпечити раціональну величину кутової швидкості обертання гондоли.

1. Кудря С.А., Кузнечов Н.П., Сахно Б.Г. Опыт использования ветровых електрических установок в Украине. Альтернативная энергетика и экология. 2011. № 8. C. $50-53$.

2. Фатеев Е.М. Ветродвигатели. Л. ВИМЭ. 1946. 244 с.

3. Головко В.М., Коханєвич В.П., Шихайлов М.О. Аналіз систем орієнтації ротора вітроустановки малої потужності . Відновлювана енергетика. 2015. № 2. С. 55-60. 
4. Вашкевич К.П., Волостных В.Н. К расчету поворота на ветер головки ветродвигателя с помощью хвоста. Промышленная аэродинамика. 1959. № 13. С. 91-105.

5. Франкфурт М.О. Аэродинамическое регулирование ветродвигателя выводом ветроколеса из-под ветра. Промышленная аэродинамика. 1964. № 26. С. 5-46.

6. Мосалев В.Ф. Об изгибе упругой лопасти гироскопическим моментом при ориентации поворотной головки ветродвигателя на ветер хвостом. Труды ВНИИЭМ. 1970. Т. № 34. С. 78-93.

7. Кузьо I.В, Корендій В.М. Динаміка систем орієнтації вітроколіс.Вісник Нац. ун-ту «Львівська політехніка». Динаміка, міцність та проектування машин і приладів. 2012 № 730: С. 51-57.

8. Головко В.М., Коханєвич В.П., Шихайлов М.О., Марченко Н.В. Вплив параметрів системи орієнтації ротора 3 використанням конструктивної схеми підпружиненого хвоста на статичні характеристики вітроустановки Відновлювана енергетика. 2015. № 3. С. 30-39.

9. Головко В.М., Коханєвич В.П., Шихайлов М.О Математична модель системи орієнтації ротора вітроустановки флюгерною площиною. Відновлювана енергетика. 2017. № 3. С. 48-54.

\section{REFERENCES}

1. Kudrya S.A., Kuznetsov N.P., Sakhno B.G. Opyt ispolzovaniya vetrovykh yelektricheskikh ustanovok v Ukraine. [Experience of using wind power plants in Ukraine] Alternativnaya energetika i ekologiya. 2011. No. 8. Pp. 50-53. [in Russian].

2. Fateyev Ye.M. Vetrodvigateley. [Wind turbines] L.VIME. 1946. 244 p. [in Russian].

3. Golovka V.M., Kokhanevich V.P., Shikhaylov N.A. Analiz sistem oriyentatsii rotora vetroustanovki maloy moshchnosti. [Rotor orientation system analysis of a low capacity wind turbine]. Vidnovluvana energetika. 2015. No. 2. Pp. 55-60. [in Ukrainian].

4. Vashkevich K.P., Volostnykh V.N. K rascheta povorota na veter golovki vetrodvigateley s pomoshch'yu khvosta. [To the calculation of the rotation of the wind turbine head with the tail]. Promyshlennaya aerodinamika. 1959. No. 13. Pp 91-105. [in Russian].

5. Frankfurt N.A. Aerodinamicheskoye regulirovaniye vetrodvigateley vyvodom vetrokolesa iz-pod vetra [Aerodynamic regulation of a wind turbine by removing a wind wheel from under the wind]. Promyshlennaya aerodinamika. 1964. No. 26. Pp 5-46. [in Russian]

6. Mosalev V.F. Ob izgibe uprugoy lopasti giroskopicheskim momentom pri oriyentatsii povorotnoy golovki vetrodvigateley na veter khvostom. [On the bending of an elastic blade with a gyroscopic moment when the rotating head of a windmill is oriented to the wind with a tail]. Trudy VNIIEM. 1970. T. No. 34. Pp. 78-93. [in Russian].

7. Kuze I.V., Korendiy V.M. Dinamika sistem oriyentatsii vitrokolis. [Dynamics of orientation wind wheels]. Visnik Nats. un-ta «Lvovskaya politekhnika». Dinamika, prochnost i proyektirovaniye mashin i priborov. 2012. No. 730. Pp. 51-57. [in Ukrainian].

8. Golovko V.M., Kokhanevich V.P., Shikhaylov N.A., Marchenko N.V. Vliyaniye parametrov sistemy oriyentatsii rotora $\mathrm{s}$ ispolzovaniyem konstruktivnoy skhemy podpruzhinennogo khvosta na staticheskiye kharakteristiki vetroustanovki. [The effect of rotor orientation system parameters with a spring-loaded tail constructive scheme over static characteristics of the wind turbines]. Vidnovluvana energetika. 2015 No. 3. Pp. 30-39. [in Ukrainian]

9. Golovko V.M., Kokhanevich V.P., Shikhaylov N.A. Matematicheskaya model' sistemy oriyentatsii rotora vetroustanovki flyugernoy ploskostyu. [Mathematical model of the rotor orientation system of the wind turbine with a vane]. Vidnovluvana energetika. 2017. No. 3. Pp. 48-54. [in Ukrainian].

\section{МАТЕМАТИЧЕСКАЯ МОДЕЛЬ СИСТЕМЫ ОРИЕНТАЦИИ РОТОРА ВЕТРОУСТАНОВКИ ЗА СЧЕТ СОБСТВЕННОЙ ПАРУСНОСТИ РОТОРА}

В.М. Головко, докт. техн. наук, проф., В.П. Коханевич, канд. техн. наук, Н.А. Шихайлов науч. сотр.

Институт возобновляемой энергетики НАН Украины, 02094, ул. Г.Хоткевича, 20А, г. Киев, Украина.

Несмотря на значительный опыт в проектировании ветроустановок малой мочности в процессе их эксплуатации возникают разрушения отдельных элементов установки, которые могут привести к разрушению установки в иелом. Одним из важных факторов, что приводит к разрушению элементов, в частности лопастей, является гироскопические нагрузки, возникающие 6 лопастях при ориентаиии ротора по направлению воздушного потока. При этом необходимо заметить, что перед конструкторами стоит определенная дилемма. C одной стороны увеличение угловой скорости приводит $к$ уменьшению энергетических потерь при ориентации ротора, а с другой - к увеличению гироскопических нагрузок в лопасти.

На сегодняшний день в ряде работ предложены математические модели систем ориентачии ротора по направлению воздушного потока за счет флюгерной плоскости хвоста. При этом используются различные конструктивные схемы данной системы ориентации ротора, такие как подпружиненный хвост, хвост на косом шарнире и другие. Система ориентации ротора за счет собственной парусности ротора практически неисследованная и требует теоретических разработок и последуюшей их экспериментальной проверки.

В данной работе предлагается разработать математическую модель системы ориентации ротора ветроустановки за счет собственной парусности ротора с учетом ряда параметров и характеристик данной системь ориентации. Предложенная математическая модель ориентации ротора позволила получить уравнения для расчета угловых скоростей ориентации ротора 6 зависимости от скоростей ветра, угла отклонения ротора от направления воздушного потока и ряда конструктивных параметров системы ориентачии ротора. Полученные угловые скорости ориентации ротора позволяют определить энергетические потери и гироскопические нагрузки на элементы конструкиии ветроустановки в прочессе ориентачии ротора. Данные уравнения также позволяют определить параметры, которыми можно воздействовать на величину угловой скорости ориентачии ротора, такие как расстояние от оси вращения гондоль к плоскости ротора и коэффициент демпфирования соответствуюших устройств, позволяет выбрать рачиональную величину угловой скорости ориентачии ротора с учетом возможных потерь выработки ветроустановкой и величин гироскопических нагрузок 6 лопастях и элементах гондоль. Библ. 9, рис. 1.

Ключевые слова: ветроэнергетика, ветроустановка ориентация ротора за счет собственной парусности.

Стаття надійшла до редакції 08.01.20 Остаточна версія 11.06.20 